\title{
Power Measurement and Data Logger with High- Resolution for Industrial DC-Grid Application
}

\author{
Peteris Apse-Apsitis (Lead Researcher, Riga Technical University), Armands Senfelds (Researcher, Riga Technical \\ University), Ansis Avotins (Researcher, Riga Technical University), Arturs Paugurs (PhD student, Riga Technical \\ University), Marcis Prieditis (PhD student, Riga Technical University)
}

\begin{abstract}
Power and energy measurement and monitoring is a key factor for many industries in terms of energy and cost efficiency evaluation. Due to trends of Smart Grid concept application in industrial environment, including decentralized DC-Grid implementation, for precise evaluation - faster and lowcost measurement equipment is needed. Manufacturing industry widely uses industrial robots that have dynamic load characteristics for which faster measurement equipment is needed.

This paper gives a brief description of the developed power measurement equipment, its structure and interconnection with industrial Profinet network. Further as a testing method steady state and dynamic loads are selected and analyzed. For testing, specially created industrial DC-Grid testing environment and equipment was used. Testing results show that the selected method and idea is working and is able to measure dynamic loads with high resolution. For other industrial load types there is a discussion going on about the issue of how detailed the resolution is needed in industrial SmartGrids, as energy forecast is a new trend in robotic industry and manufacturing planning.
\end{abstract}

Keywords - Smart Grids; Industrial power systems; Power measurement.

\section{INTRODUCTION}

Emerging trends towards intensive enhancement of electrical power supply systems for integration of new types of electrical power generation solutions, extensive power and related operating information flow management and intelligent utilization of electrical infrastructure can be summarized as Smart grid. The existing power distribution system is AC based, but with Smart Grid concept, and DC source integration to the AC grid raises the question of DC-Grid implementation feasibility, where some preliminary research shows advantages of DC-Grid implementation [1]. Some studies show that the powering equipment from $\mathrm{AC}$ or $\mathrm{DC}$ based equivalent power source in home or office application [2]-[4] the DC-Grid is more efficient due to the fact that less conversion stages are used and the improved network quality.

In Smart Grid context electric car or intelligent battery energy storage system [5] can be consumer or producer generally referred as term - prosumer in several articles [6] [9], by means that regenerative braking energy can be stored and re-used on demand. Integration of such new power sources in Smart Grid creates not only a problem of safety issues such as fast DC circuit breakers [10] and over current protection [11], but also the need for fast and cheap energy flow control instruments for distributed power metering and monitoring applications [12], [13]. The ability to obtain data on instantaneous power consumption or generation is crucial for operation of any higher level system. Since many power consumer devices today can be referred to as smart or advanced electromechanical devices, regardless of their task or operation principles, it could be said that they are based on one or several electro-technological molecules as presented in Fig. 1.

\section{TARGET SYSTEM STRUCTURE}

The same is true also for electric smart grids, regardless of their size, where actuators can be seen as power generating units and sensors provide information about power flow. Various enabling technologies are already available on the market, considering methods of data transmission within power system, including embedded power line communication systems, various telecommunication standards and industrial communication protocols. By increasing the share of power measurement equipment units within power systems, in respect to existing setups of nowadays, such parameters as reliability, self-consumption and investment costs have significant role in decision making of major installation of such devices. New developments along with existing AC distribution system approach considering DC power supply in various applications present the demand for adaptation of existing power measurement equipment. The practical application of power meter unit has been done considering industrial DC microgrid as a case study scenario of intelligent power supply system.

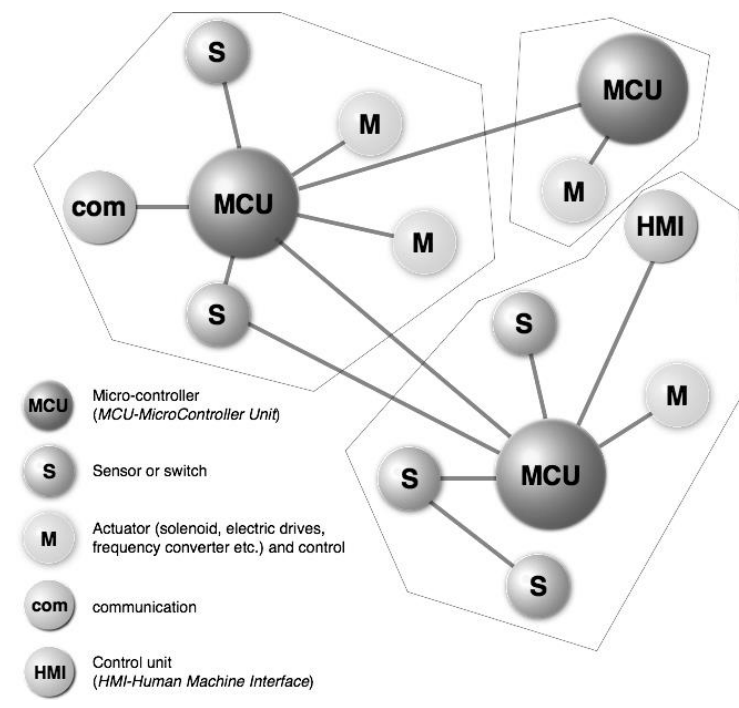

Fig. 1. Visual example of electro-technological molecule structure. 


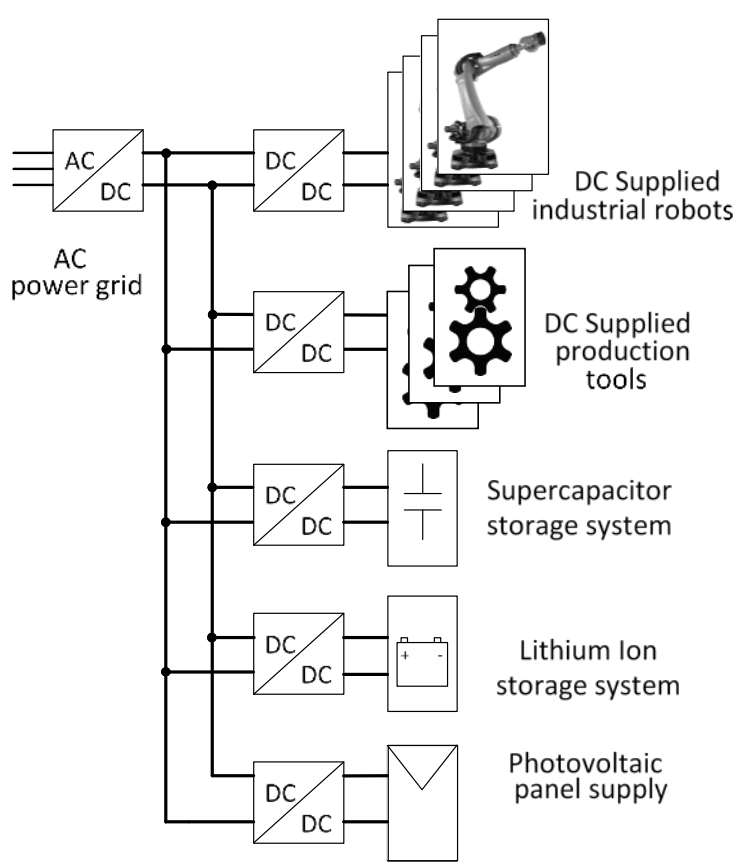

Fig. 2. Example of industrial DC microgrid structure

The concept of such innovative electrical infrastructure has been developed within AREUS project [14] considering $600 \mathrm{~V}$ DC voltage based energy distribution, recuperation, storage and exchange operation within manufacturing application. The principal structure of such system is presented in Fig. 2.

A lot of electrical energy consumers or sources operate on DC-Grid. AC/DC or DC/AC converters make it possible to use them also in AC environment. Energy storage devices like super capacitors, batteries, hydrogen cells, etc. allow to store and re-use energy and are designed for DC applications. Such devices are connected to the $\mathrm{DC}$ or $\mathrm{AC}$ grid via unidirectional or bidirectional energy flow converters. In order to control energy flow this equipment directly points out the necessity to know energy and power values - instantly or in milliseconds, for correct and effective converter and stable power-grid operation. Moreover, simultaneous energy flow monitoring near DC microgrid consumers and energy sources as well as AC grid allow to determine system efficiency and evaluate the weak points of the system from the energy flow point of view. The abovementioned allows making changes in the device workflow in order to increase its efficiency, if possible or necessary. Potential application for intelligent system power flow balancing for manufacturing process is presented in [15].

\section{MEASUREMENT SySTEM DEVELOPMENT}

Energy measurement device can be seen as a system combined of a set of several subsystems designed for specific tasks. The workflow of energy measurement device can be divided into a sequence of acquisition of electrical quantity, evaluation and information flow within communication infrastructure. In the particular case communication within industrial protocol Profinet was advantageous since application is within automated manufacturing industry case.

\section{A. Suggestions on Electrical Energy Measurement}

Typically energy consumption calculations are based on instant power values, especially if consumer generates nonsinusoidal current form. Instant current and voltage value readings (samples) are made and following multiplication is used to calculate instant power, average power or consumed energy [16], [17]. Sampling rate must be at least $4.2 \mathrm{kHz}$ or 42 samples per 1/2T according to standard EN 61000-3-2 [21] and Nyquist frequency.

Active and reactive power measurements and calculations is a continuous dispute between scientists for non linear (or non sinusoidal) waveforms. In general, for power analysis two main approaches exist, where one is Budeanu's definition based on current and voltage value harmonic parameters (1), or Fryze's definition (2) based on voltage and current RMS (Root Mean Square) values, calculating power by active and reactive component values.

$$
\begin{gathered}
P=U_{0} I_{0}+\sum_{n=1}^{\infty} U_{n} I_{n} \cos \varphi_{n} ; \quad Q=\sum_{n=1}^{\infty} U_{n} I_{n} \sin \varphi_{n} \\
\lambda=\frac{P}{S}=\frac{\frac{1}{T} \int_{0}^{T} u i d t}{\sqrt{\frac{1}{T} \int_{0}^{T} u^{2} d t} \sqrt{\frac{1}{T} \int_{0}^{T} i^{2} d t}}
\end{gathered}
$$

Another method is the averaging of voltage and current values via multi-order delta-sigma modulation and the following multiplication [18]. Thus electrical energy measuring and monitoring device installation near every consumer or generator is very expensive. Several methods are proposed to lower the costs, for example [19], [20], in order to achieve widespread installations of electrical energy measuring/monitoring devices. The main disadvantage is the necessity of separate low power source for measuring IC's power feed and resulting increase in measuring device selfconsumption. Moreover, high speed analog-digital converters read grid noise (and generate sampling noise by themselves) and high order filtering must be applied for correct results.

Thus there is a difference between AC and DC energy measurements due to AC and DC environment difference (e.g. power factor existing in AC grid and not existing in DC grid), especially if bi-directional energy flow takes place.

Non-even sampling energy consumption measuring method was proposed to overcome the abovementioned disadvantages. The method allows measuring of bi-directional AC or DC energy flow, design low self power consumption devices and perform measurements down to every $10 \mathrm{~ms}$ for DC grids or $20 \mathrm{~ms}$ for AC grids or several grids for simultaneous readings.

\section{B. Non-even Sampling Method}

According to non-even sampling method [16] the amount of consumed or generated electrical energy during the predefined period of time is directly proportional to the sum of current samples over this time multiplied by voltage-frequency 
transfer coefficient, if current sampling rate is modulated by applied voltage value (Fig. 3).

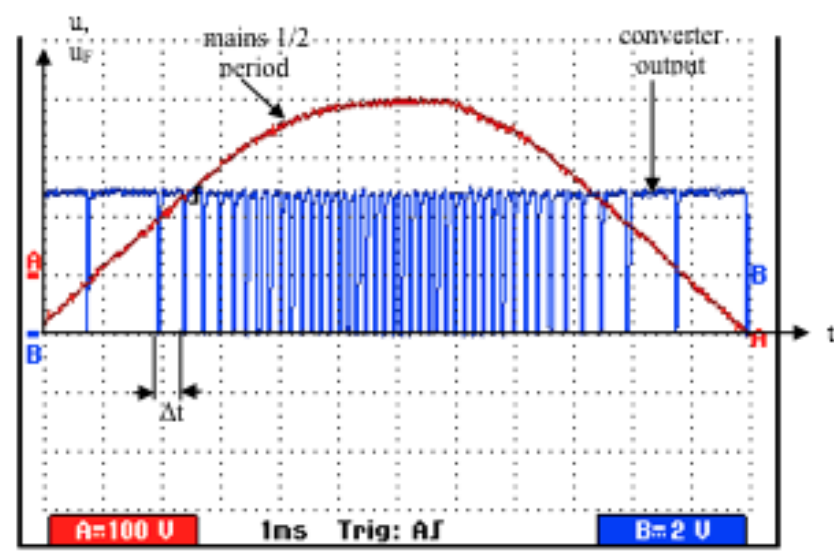

Fig. 3. Example of voltage dependent sampling rate operation.

Converters do not utilize any transformers or voltage dividers and are electrically isolated from micro-controller circuit.

\section{Industrial Protocol Selection and Integration}

There are various industrial communication protocols and their evaluation [22], [23], but Profinet IO is the leading standard for industrial communication, as it is simple in use and installation, and implementation of PROFIenergy [24] gives benefit in terms of energy monitoring and evaluation. It can be configured to deliver data from one device to another in $1 \mathrm{~ms}$ or faster (Isochroous Real Time Profinet IO) [25]. PM (Power Moidule) is connected to Profinet IO via Anybus CompactCom (AnybusCC) module from HMS. This module enables the developer of the embedded system to connect to Profinet IO without advanced knowledge of functionality of Profinet IO.

Data cables in Profinet system are normally made of copper wires. And $100 \mathrm{~m}$ cable can be crossed by 1 bit in $0.5 \mu \mathrm{s}$. Bridge delay (delay present in switch) depends on conformance type of Profinet IO and its maximum value can be from $3 \mu \mathrm{s}$ (IRT) to $10 \mu \mathrm{s}$ (RT). Time of package transmission from the device depends on the length of telegram. If the telegram which consists of 84 bytes is sent (shortest possible Ethernet telegram) then $6.72 \mu \mathrm{s}$ are necessary. If telegram is 1538 bytes long then the transmission time is $123.04 \mu$ s [26]. For example, if data has to cross 4 switch devices and wire connections are $100 \mathrm{~m}$ long (Fig. 4) and the shortest Ethernet packet is used then data transmission time can be calculated as shown in (3):

$$
4 \cdot(10 \mu \mathrm{s}+5.0 \mu \mathrm{s})+72.6 \mu \mathrm{s}=132 \mu \mathrm{s}
$$

Time that is needed for data to arrive from AnybusCC to PLC in case of RT Profinet IO configuration, 1 switch, $100 \mathrm{~m}$ long connecting wire and telegram size of 1538 bytes should not exceed $0.5+10+123.04=133.54 \mu \mathrm{s}$. Another part of circuit that introduces delay is PM data sending to AnybusCC. The fastest and most complex) is the parallel connection to AnybusCC. That would result in approximately $30 \mathrm{~ns}$ long delay time [27]. By summing up all possible delay times it can be estimated that total delay of data is shorter than shortest possible bus-cycle time - $250 \mu$ s (IRT Profinet IO), which does not present critical influence on system functionality. In one second data from one PM to PLC can be sent $1 \mathrm{~s} / 250 \mu \mathrm{s}=$ 4000 times, with largest possible delay of $133.54 \mu$ s.

\section{EXPERIMENTAL SETUP AND MEASUREMENT METHODS}

Verification of the developed active power measurement system has been realized within industrial DC microgrid operation with nominal voltage of $600 \mathrm{~V}$ (Fig. 5).

The central element of DC microgrid supply is the common AC/DC interface converter (1) of nominal power $55 \mathrm{~kW}$ for bidirectional power flow operation with common current sensing technology available in industry, but keeping in mind that it is also possible to use sensorless topologies as described in [28]. The converter performs the task of stable $600 \mathrm{~V}$ voltage supply on DC circuit of microgrid. The AC side power flow is controlled for power factor correction and current harmonic reduction by means of applied passive filter unit.

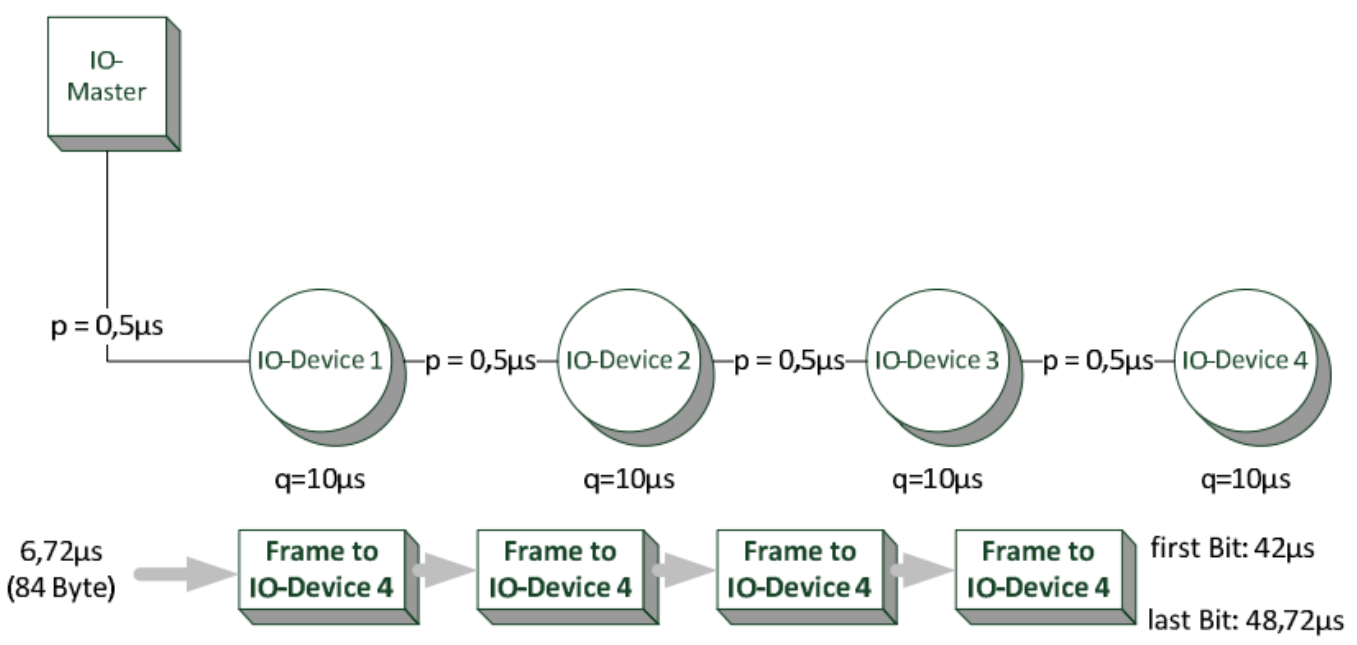

Fig. 4. Calculation of data transmission time. 


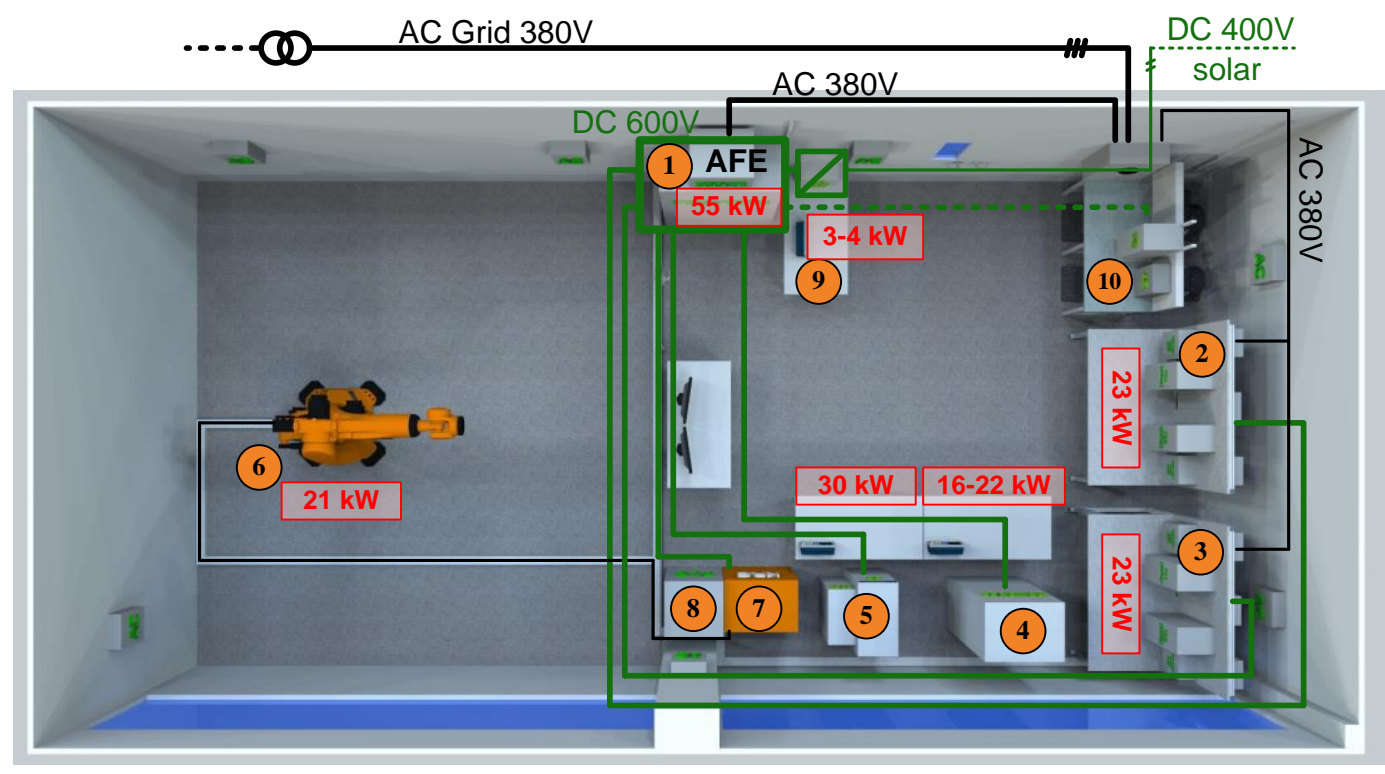

Fig. 5 Experimental verification laboratory hardware testing layout of industrial DC-Grid infrastructure.

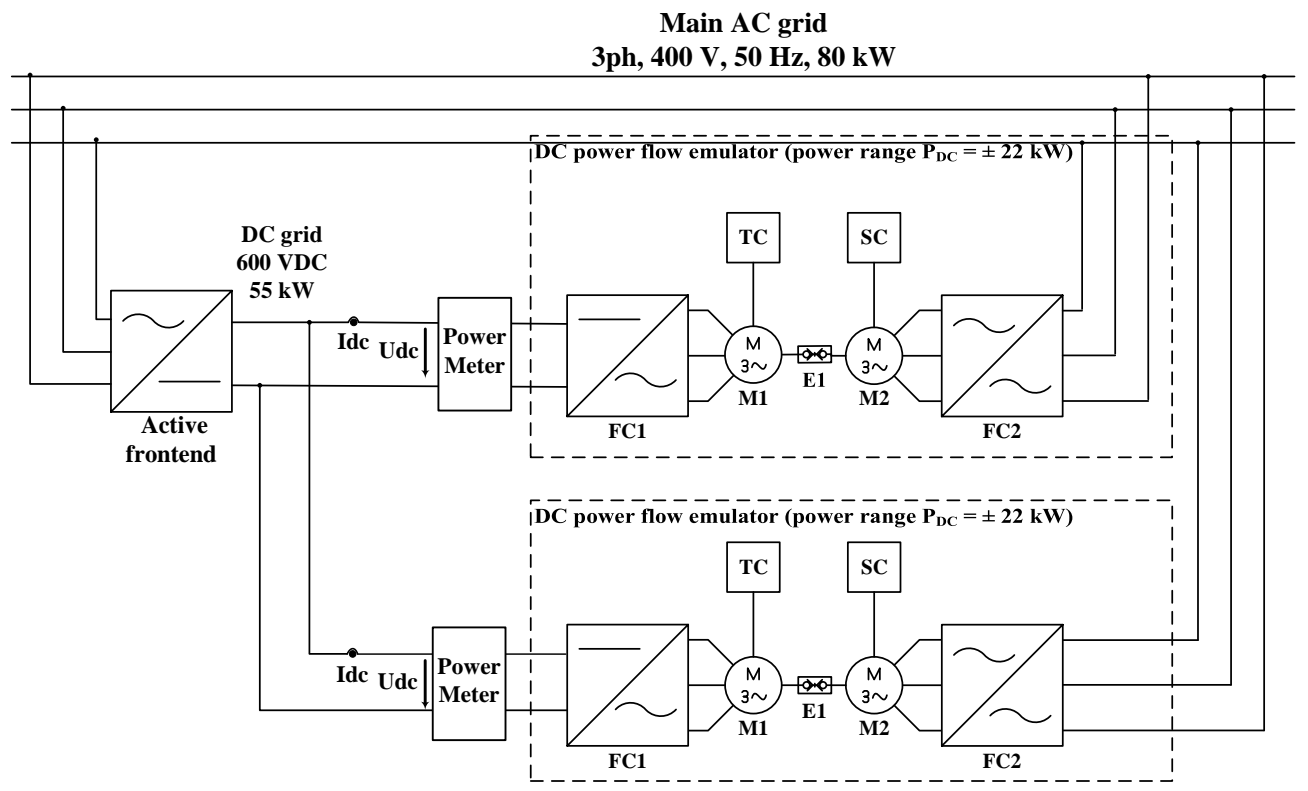

Fig. 6. Structure of DC testing system and measurement points.

The power flow within DC microgrid is enabled by means of drive stand units for power flow emulation (2 and 3). The power range of each of power emulator unit is within $22 \mathrm{~kW}$ for both consuming and regenerating energy into common DC microgrid. Such equipment has been designed in order to replicate various power consumption profiles that appear in industrial manufacturing operations taking also possible potential of recuperated energy to be reused within common DC power grid. The operating power profiles applied for dynamic verification of power meter equipment were obtained from industrial robotic manufacturing application. The setup for DC system testing with 2 dynamic power loads is presented in the schematic (Fig. 6).

As shown in Fig. 5, for future testing it is planned also to use other load types, such as solar panel DC/DC converters
(9), Lithium-ion battery energy storage system (4), supercapacitor energy storage system (5), and also a $600 \mathrm{~V}$ DC powered industrial robot prototype (6) controlled by robot controller (7) and industrial cell Master PLC controller (8), as well as wind generator (PMSG) (10) driven by AC motor can be used as testing object.

For laboratory measurements three tests were created and measured under steady state load, dynamic load (real robot consumption profile), and the comparison with data was obtained through Profinet network.

The developed power measurement hardware testing prototype is shown in Fig. 7 where it has measurement module [12], [13] with two communication outputs, where AnyBus module is devoted to Profinet communication with Programmable Logic Controller and additional optical circuit 
is for communication and data transfer to personal computer. The device is powered from $24 \mathrm{~V}_{\mathrm{DC}}$ voltage, voltage measurements can be done in the range of $200-700 \mathrm{~V}_{\mathrm{DC}}$ and nominal is $600 \mathrm{~V}_{\mathrm{DC}}$, current measurements in the range +/-70 A, max measurement resolution is $1 \mathrm{~ms}$, but nominal resolution is $20 \mathrm{~ms}$.

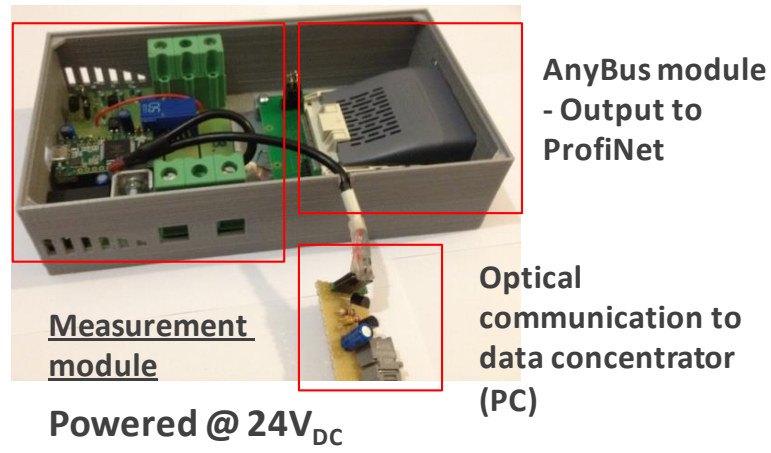

Fig. 7. Developed power measurement hardware testing prototype.

The novel power measurement equipment was compared to the existing laboratory grade Newtons N4L power analyzer with power measurement functionality. In order to verify any existing deviation of the obtained data extracted by means of power measurement prototype with respect to existing and calibrated equipment by manufacturer N4L, model PPA3340 data was collected at steady state operation within power range of $18 \mathrm{~kW}$ recuperating to $20 \mathrm{~kW}$ consumption, by means of parallel measurements.

In order to evaluate dynamic response of power meter prototype the electrical quantities of voltage and current was obtained by means of oscilloscope along with direct power measurement of measurement device. In this case a motor drive based system (see Fig. 6) was used to test the AREUS DC power meter. The system can dynamically control the DC power flow in both consumption and generation modes within its respected power boundaries of $-22 \mathrm{~kW}$ to $+22 \mathrm{~kW}$.

The power flow control is realized by dynamically changing the torque of an asynchronous machine, whilst keeping its rotational speed constant (4).

$$
P_{D C} \approx T \cdot \omega
$$

where

$P_{D C} \quad$ power measured at the DC bus of the frequency converter driving the asynchronous machine;

$T$ mechanical torque;

$\omega \quad$ rotor angular velocity.

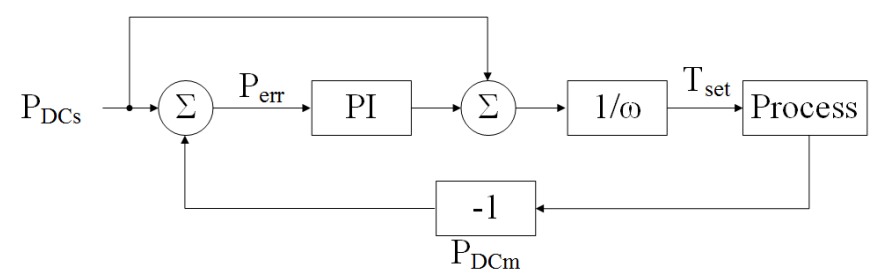

Fig. 8. Block schematic of the motor drive system's power flow control loop.

$$
T_{s e t}=\left(P_{e r r} \cdot W_{P I}+P_{D C s}\right) \cdot \frac{1}{\omega}
$$

where

$T_{\text {set }} \quad$ the set torque value;

$P_{\text {err }}$ the difference between the set and the measured DC power;

$W_{\text {PI }}$ the transfer function of a parallel PI regulator;

$P_{D C s}$ the set power value.

AREUS DC power meter is implemented in the feedback loop of the system's power flow controller (Fig. 8), which enables the inclusion of various regulation methods, thus optimizing the system's performance. The control method used in equation (5) enables $100 \%$ precise recreation of a real industrial robot electrical load (consumption profile), thus giving real-life dynamic testing environment for power measurement device.

PROFINET Data acquisition network structure and functionality of CMs (communications module) has been tested in the line structure of Profinet IO network (Fig. 9).

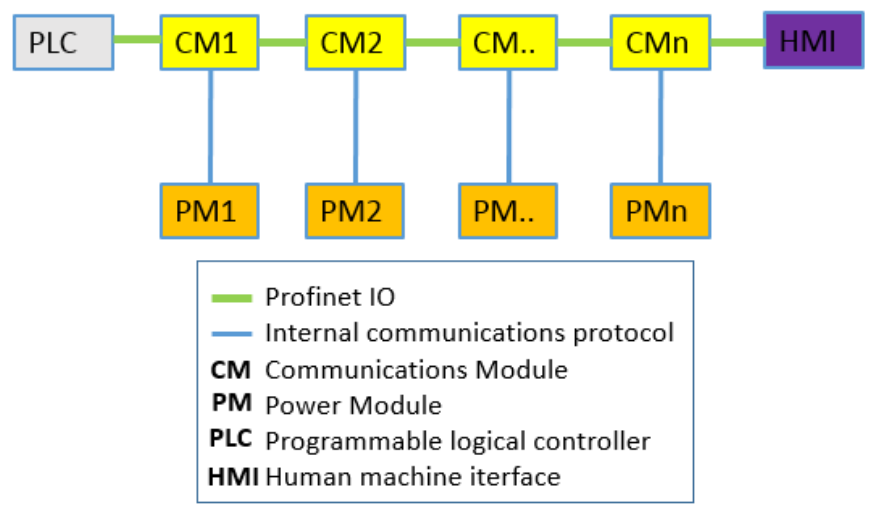

Fig. 9. Line structure of Profinet IO network.

The structure is possible because the Profinet IO 2-Port Plug-In Module (AnybusCC) has a built in switch. For tests, $\mathrm{CM}$ in conjunction with PM has been used, which is dedicated to measure power at the nodes of DC busses of industrial robots. As a PLC has been used CPU 1212C from Siemens, IR Profinet IO standard and for visualization of system functionality Siemens TIA portal integrated plotting tool has been used and afterwards data has been extracted and formatted with MS Excel (Fig. 12).

\section{EXPERIMENTAL RESULTS AND ANALYSIS}

The novel DC power meter was connected in series between the AFE 600 VDC output and the motor drive system's DC input and measured the momentary DC power values. Two types of verification experiments were performed. In the first case the dynamic power flow of an industrial robot was emulated with the motor drive system. The DC power meter's averaging time was set to $15 \mathrm{~ms}$. As a comparison, the DC power was measured with Rigol DS1104Z oscilloscope, using PROSyS CP 35 current probe and Tektronix P5200 differential voltage probe. The logged data from both measuring devices are summarized in Fig. 10. 


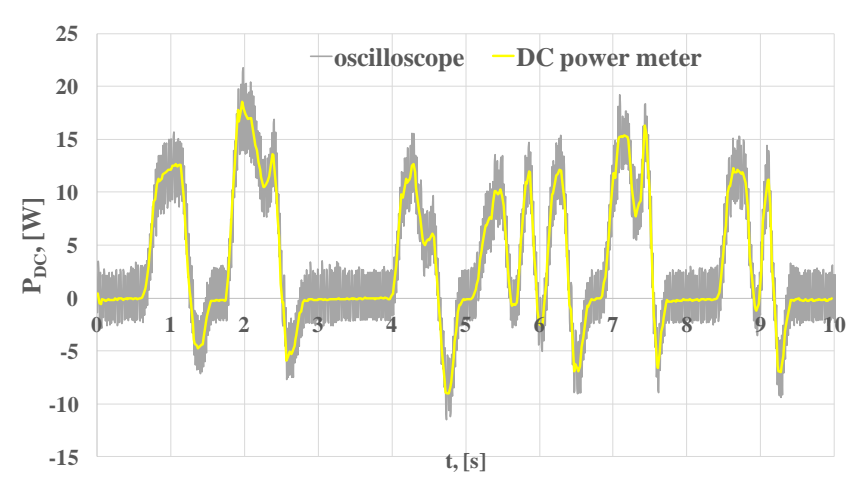

Fig. 10. The first case: dynamic power flow measurements from the novel DC power meter and the Rigol DS1104Z oscilloscope.

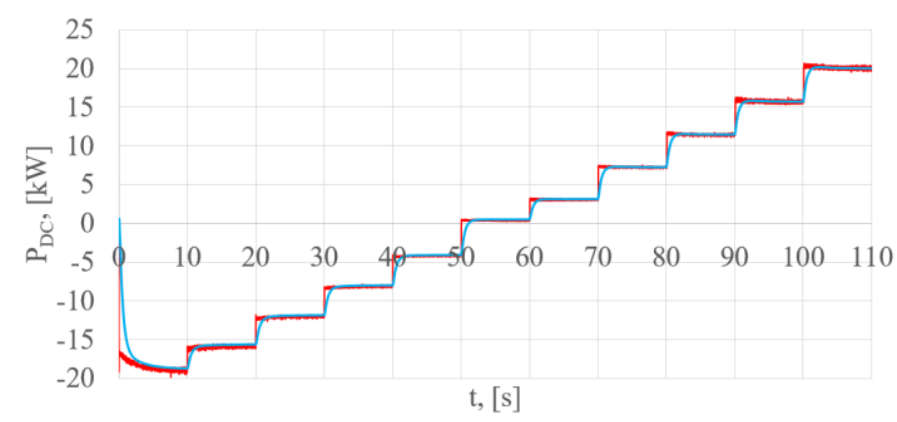

Fig. 11. The second case: constant power steps throughout the motor drive system's power range. Measurements from the novel DC power meter (red line) and the N4L PPA5530 power analyzer (blue line).

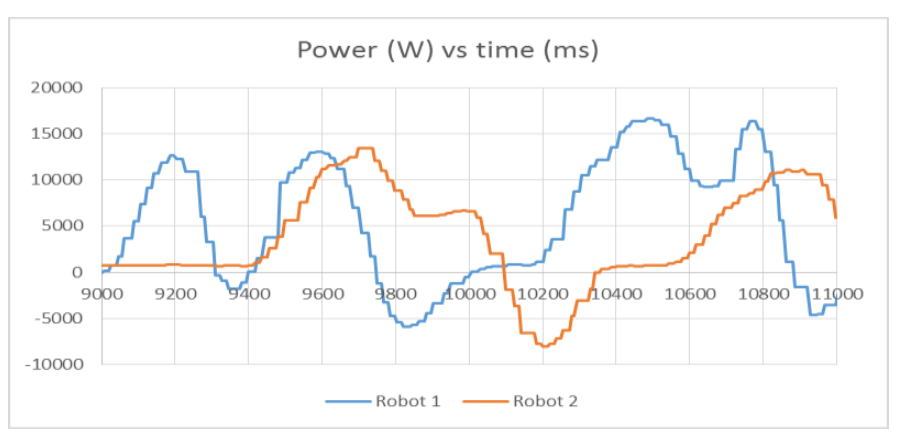

Fig. 12. Instant power consumption of two simultaneously working robots acquired through Profinet.

TABLE I

Relative Deviation OF THE NOVEL DC POWER METER IN COMPARISON WITH THE N4L PPA5530 POWER ANALYZER

\begin{tabular}{|l|l|}
\hline $\boldsymbol{P}_{\boldsymbol{D C}}$ (DC power meter), [W] & Deviation, [\%] \\
\hline-18974.84 & $1.44 \%$ \\
\hline-15920.19 & $1.32 \%$ \\
\hline-12037.49 & $1.32 \%$ \\
\hline-8169.73 & $1.97 \%$ \\
\hline-4203.16 & $3.06 \%$ \\
\hline 415.60 & $21.16 \%$ \\
\hline 3061.77 & $3.22 \%$ \\
\hline 7261.49 & $0.99 \%$ \\
\hline 11491.05 & $0.69 \%$ \\
\hline 15798.17 & $0.86 \%$ \\
\hline 20131.46 & $0.84 \%$ \\
\hline
\end{tabular}

In the second case verification tests were performed by applying constant power values throughout the motor drive system's power range (Fig. 11). In this case, the novel DC power meter measurements were compared with data from N4L PPA5530 power analyzer (voltage measurement internal, current measurement with HF100 current shunt). The PPA5530 was set to DC coupling, $5 \mathrm{~Hz}$ filtering. Acquisition window was set to $15 \mathrm{~ms}$.

\section{CONCLUSION}

In both steady and dynamic testing cases the developed power measurement equipment shows very fast, precise and stable measurements that are even faster than N4L PPA5530 power analyzer. The measurement deviation in work range is within acceptable range.

Implementation of optical communication interface allows stable real-time measurement data transmission to the personal (PC) computer database, thus eliminating connection problems to PC due to various electromagnetic interference (EMI) radiations, caused by typical industrial equipment.

$\mathrm{CM}$ working speed is fast enough to replicate power curves of industrial robots, although PM is not connected directly to AnybusCC by parallel connection, but through one intermediate node and serial connections.

Next measurements should be done in other non-linear load situations and compared against the measurements done with faster and more precisely calibrated equipment. In case Profinet and PLCs are used, there is a discussion about the time resolution for dynamic loads and PLC ability to send the necessary data. At these testing loads, the $20 \mathrm{~ms}$ resolution is enough for energy calculation, but more load types should be tested to validate this approach of energy forecast.

Equipment testing within industrial application case is foreseen for determination of optimal functionality followed by price estimation for the prototype modified for typical electronic equipment production process.

\section{ACKNOWLEDGEMENT}

This research is supported by Latvian National Research Programme project LATENERGI.

\section{REFERENCES}

[1] D. J. Hammerstrom, "AC Versus DC Distribution SystemsDid We Get it Right?" in Power Engineering Society General Meeting, 2007. IEEE, pp. 1-5, 24-28 June, 2007. http://dx.doi.org/10.1109/pes.2007.386130

[2] A. Sannino, G. Postiglione, M. H. J. Bollen, "Feasibility of a DC network for commercial facilities," IEEE Trans. Ind. Appl., vol. 39, no. 5, pp. 1499-1507, Sept.-Oct. 2003.

http://dx.doi.org/10.1109/TIA.2003.816517

[3] D. Deaconu, A. Chirila, M. Albu, L. Toma, "Studies on a LV DC network," in 2007 European Conf. on Power Electronics and Applicat., 2-5 Sept. 2007, pp. 1-7. http://dx.doi.org/10.1109/epe.2007.4417634

[4] K. Techakittiroj, V. Wongpaibool, "Co-existance between ACDistribution and DC-Distribution: In the View of Appliances," in 2nd Int. Conf. on Comput. and Elect. Eng., 2009, ICCEE '09., 28-30 Dec. 2009, vol. 1, pp. 421-425. http://dx.doi.org/10.1109/iccee.2009.85

[5] Tesla Home Battery "Powerwall" system [Online]. Available: https://www.teslamotors.com/powerwall [Accessed: 27.12.2015].

[6] R. W. De Doncker, "Future DC Grid Technology for more Decentralized Power Production and Renewable Power Supplies," presented at the IEEE PEDG2012 conference, 28 June 2012. 
[7] S. Grijalva, M. U. Tariq, "Prosumer-based smart grid architecture enables a flat, sustainable electricity industry," in 2011 IEEE PES Innovative Smart Grid Technologies, ISGT, pp. 1-6, 17-19 Jan. 2011. http://dx.doi.org/10.1109/isgt.2011.5759167

[8] S. Grijalva, M. Costley, N. Ainsworth, "Prosumer-based control architecture for the future electricity grid," in 2011 IEEE Int. Conf. on Control Applications, CCA, pp. 43-48, 28-30 Sept. 2011. http://dx.doi.org/10.1109/cca.2011.6044467

[9] F. Khoucha, M. Benbouzid, Y. Amirat, A. Kheloui, "Integrated energy management of a plug-in electric vehicle in residential distribution systems with renewables," in 2015 IEEE 24th Int. Symp. on Ind. Electron., ISIE, pp. 717-722, 3-5 June 2015. http://dx.doi.org/10.1109/isie.2015.7281557

[10] J. Yang, "Protection issue discussion of DC network development: Circuit breaker or fault-tolerant converter," in Developments in Power Systems Protection, 2012. DPSP 2012., pp. 1-6, 23-26 April 2012. http://dx.doi.org/10.1049/cp.2012.0085

[11] M. E. Baran, N. R. Mahajan, "Overcurrent Protection on VoltageSource-Converter-Based Multiterminal DC Distribution Systems," IEEE Trans. Power Delivery, vol. 22, no. 1, pp. 406-412, Jan. 2007. http://dx.doi.org/10.1109/TPWRD.2006.877086

[12] P. Apse-Apsitis, A. Avotins, L. Ribickis, "A different approach to electrical energy consumption monitoring," in 2014 16th European Conf. on Power Electron. and Applicat., EPE'14-ECCE Europe, pp. 1-5, 26-28 Aug. 2014. http://dx.doi.org/10.1109/epe.2014.6910970

[13] P. Apse-Apsitis, A. Avotins, L. Ribickis, "Bidirectional DC/AC energy flow measurement," in 2015 IEEE 5th Int. Conf. on Power Engineering, Energy and Electrical Drives, POWERENG, pp. 465-468, 11-13 May 2015. http://dx.doi.org/10.1109/powereng.2015.7266362

[14] M. Pellicciari, A. Avotins, K. Bengtsson, G. Berselli, N. Bey, B. Lennartson, D. Meike, "AREUS - Innovative hardware and software for sustainable industrial robotics," in 2015 IEEE Int. Conference on Automation Science and Engineering, CASE, pp. 13251332, 24-28 Aug. 2015. http://dx.doi.org/10.1109/coase.2015.7294282

[15] A. Senfelds, M. Vorobjovs, D. Meike, O. Bormanis, "Power smoothing approach within industrial DC microgrid with supercapacitor storage for robotic manufacturing application," in 2015 IEEE Int. Conf. on Automation Science and Engineering, CASE, pp. 1333-1338, 24-28 Aug. 2015. http://dx.doi.org/10.1109/coase.2015.7294283

[16] Atmel AVR1631: Single Phase Energy Meter using XMEGA A, Available: http://www.atmel.com/images/doc42039.pdf

[17] P. Apse-Apsitis, A. Avotins, L. Ribickis, "System and Method for Monitoring Real Power Consumption," in International patent application WO 2013/093554 A1, published 27.06.2013

[18] S. T. English, "A Low Cost Watt-Hour Energy Meter Based on the ADE7757," Available: http://www.analog.com/static/imported-files /application_notes/AN-679.pdf

[19] P. Apse-Apsitis, A. Avotins, L. Ribickis, J. Zakis, "Development of Energy Monitoring System for Smart Grid Application," in 3rd IFIP WG 5.5/SOSOLNET Doctoral Conference on Computing, Electrical and Industrial Systems, DoCEIS 2012, Costa de Caparica, Portugal, 2012 Proceedings, Springer Berlin Heidelberg, New York, ISSN 1868-4238, ISBN 978-3-642-28254-6, pp. 347-354. http://dx.doi.org/10.1007/9783-642-28255-3_38 b

[20] P. Apse-Apsitis, A. Avotins, L. Ribickis, "Concept of Low-Cost Energy Monitoring System for household Application," in Proc. ELMAR-2011, Zadar, Croatia, pp. 149-152, ISBN: 978-953-7044-12-1.

[21] Harmonic Current Emissions, Guidelines to the standard EN 61000-3-2, Available: http://www.epsma.org/pdf/PFC20Guide_November202010.pdf

[22] E. Bassi, F. Benzi, L. Lusetti, G. S. Buja, "Communication protocols for electrical drives," in Proc. of the 1995 IEEE IECON 21 st Int. Conf. on Ind. Electron., Control, and Instrumentation, 6-10 Nov 1995, vol. 1, pp. 706-711. http://dx.doi.org/10.1109/iecon.1995.483494

[23] Siegfried, C.; Constantin, R.; Stancescu, S., "Evaluation of protocol for industrial informatics systems," in 2010 8th Int. Conf. on Commun. COMM, 10-12 June 2010, pp. 293-296. http://dx.doi.org/10.1109/iccomm.2010.5509109

[24] PI Whitepaper "The PROFIenergy profile", March 2010, PROFIBUS Nutzerorganisation e.V.(PNO), Available: http://www.profibus.com/download/brochures-white-paper/

[25] P. Ferrari, A. Flammini, D. Marioli, A. Taroni, "Experimental evaluation of PROFINET performance," in Proc. 2004 IEEE Int. Workshop on Factory Commun. Systems, 22-24 Sept. 2004, pp. 331-334. http://dx.doi.org/10.1109/wfcs.2004.1377739

[26] H. Bernhard, J. Mottok, "Real-time Behaviour of Ethernet on the Example of PROFINET"
[27] Hardware Design Guide, Anybus ${ }^{\circledR}$ CompactCom M40, Doc.Id. HMSI216-126 Rev. 1.40.

[28] A. Suzdalenko, "Current Sensorless Control of Front-end Bidirectional AC/DC Converter Based on Half-bridge Topology," Electrical, Control and Communication Engineering, vol. 4, pp. 19-25, 2013. http://dx.doi.org/10.2478/ecce-2013-0017

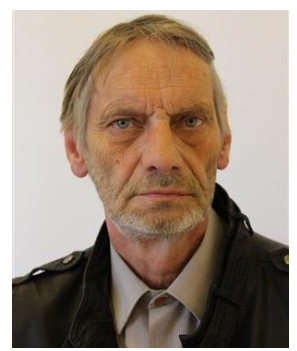

Peteris Apse-Apsitis, Dr. sc. ing., is a Lead Researcher with the Institute of Industrial Electronics and Electrical Engineering, Riga Technical University.

His main fields of scientific and research interests are connected with power electronics, robotics and mobile ICT applications

$\mathrm{He}$ is the author of many industrial solutions and applications and patented inventions.

$\mathrm{He}$ is a member of IEEE Latvia Association. Address: Azenes Street 12/1, LV-1048, Riga E-mail: Peteris.Apse-Apsitis@ rtu.lv Phone: +371 67089919

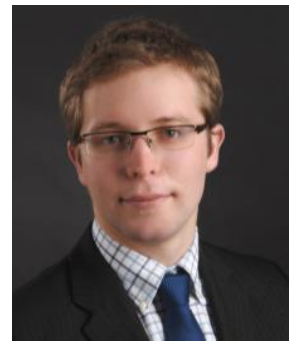

Armands Senfelds is a $\mathrm{PhD}$ student and a researcher with the Institute of Industrial Electronics and Electrical Engineering of Riga Technical University. His research interests include design and control of power electronic equipment, electrical drives and electrical mobility.

Address: Azenes Street 12/1-524, Riga, LV-1048, Latvia.

E-mail: armands.senfelds@rtu.lv

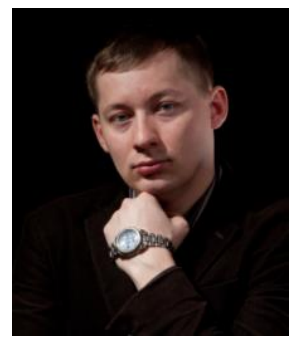

Ansis Avotins is a PhD student with the Faculty of Power and Electrical Engineering. His main field of study is autonomous LED lighting systems. Since 2004, he has been a Chief Laboratory Manager of IEEI, RTU. He is a member of IEEE and ACM associations.

Address: Riga, Azenes Street 12/1-507, LV-1048. E-mail: ansis.avotins@ rtu.lv

Phone: +371 67089919

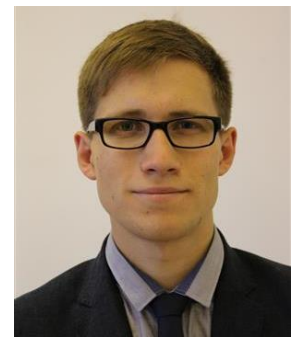

Arturs Paugurs is a PhD student with the Faculty of Power and Electrical Engineering of Riga Technical University. His research interests are industrial DC power distribution systems, power flow control and DC safety applications. Since 2013, he has been a research assistant with IEEI, RTU. He is a member of IEEE Industry Applications Society.

Address: Azenes Street 12/1-524, Riga, LV-1048,

Latvia.

E-mail: arturs.paugurs@rtu.lv

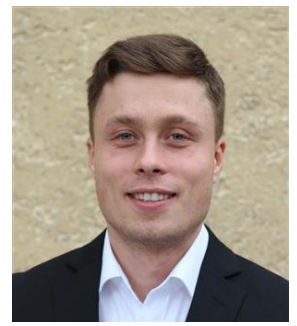

Marcis Prieditis is a $\mathrm{PhD}$ student with the Faculty of Power and Electrical Engineering of RTU. He is currently a member of research team working on efficiency improvement in industrial robotics.

$\mathrm{He}$ is a researcher and lecturer with the Institute of Industrial Electronics and Electrical Engineering of RTU.

$\mathrm{He}$ is a member of IEEE Industry Applications Society.

Address: Azenes Street 12/1-524, Riga, LV-1048, Latvia.

E-mail: marcis.prieditis@rtu.lv 